\title{
Study on a Novel Composite Eco-Friendly Corrosion and Scale Inhibitor for Steel Surface in Simulated Cooling Water
}

\author{
Defang Zeng, Wen Qin* \\ Hubei Key Laboratory of Mineral Resources Processing and Environment, School of Resource and Environmental Engineering, \\ Wuhan University of Technology, Wuhan, China. \\ Email: *qinwen0514@163.com
}

Received April 26 ${ }^{\text {th }}, 2012$; revised May 15 ${ }^{\text {th }}, 2012$; accepted June $5^{\text {th }}, 2012$

\begin{abstract}
The use of organophosphorus inhibitor is diminishing because of its toxic effects on aquatic and other life. In this study, a composite eco-friendly phosphate-free corrosion and scale inhibitor HS has been developed using hydrolyzed polymaleic anhydride (HPMA), sodium gluconate, $\mathrm{Zn}^{2+}$ synergist and sulfamic acid. And the formula ratio of each component is 9:5:4:2. The performance of the corrosion and scale inhibitor was evaluated by weight loss experiment and the static scale inhibition test, respectively. The results indicated that HS had positive corrosion and scale inhibition effect at a dosage of $40 \mathrm{mg} \cdot \mathrm{L}^{-1}$ or higher. Potentiodynamic polarization curves indicated that HS inhibits the corrosion of steel based on controlling the anodic reaction. And the surface morphology of the carbon steel was studied by scanning electronic microscope (SEM). The inhibition effects were due to the formation of protective films.
\end{abstract}

Keywords: Corrosion and Scale Inhibitor; Steel; Cooling System

\section{Introduction}

Circulating cooling water system is a commonly used instrument in industry. Two of the main operating problems of the cooling water system are corrosion and scale because of the electrochemical oxidation reduction reaction and the metal salt sediments on the metal surface [1]. Therefore, numerous inhibitors have been used in cooling water system to solve these problems [2-10].

Organophosphorus compound was a type of corrosion inhibitor of choice because of its long-term successful commercial usage and their excellent effectiveness at a wide range of conditions extensively used since 1980s [11]. However, industrial requirements for chemical compounds refer not only to their efficacy but to safety as well. The requisites for these compounds should focus on the non-mutagenic, non-carcinogenic products with characteristics more environmentally acceptable than systems currently in use [12]. So the use of organophosphorus inhibitors is diminishing because of its toxic effects on aquatic and other life [13]. Therefore, the current trend toward the inhibitors is to use more environmentally friendly phosphate-free inhibitors such as hydrolyzed polymaleic anhydride (HPMA) and $\mathrm{Zn}^{2+}$ synergist [14].

Some investigations have been reported that the effect

"Corresponding author. of sodium gluconate as an effective non-toxic corrosion and scale inhibitor for ordinary mild steel in simulated cooling water [15]. Gluconate and gluconic acid as well as sodium, calcium and zinc salts of gluconic acid are reported as successful inhibitors against corrosion of tin, iron and mild steel in near neutral media and in simulated cooling water [16].

In this paper, a multi-component phosphate-free corrosion and scale inhibitor has been prepared by sodium gluconate, hydrolyzed polymaleic anhydride (HPMA), $\mathrm{Zn}^{2+}$ synergist and sulfamic acid. The performance of the phosphate-free corrosion and scale inhibitor was evaluated by rotary hanging sheet corrosion test and static scale inhibition test. The mechanism of corrosion and scale inhibition was preliminarily investigated by corrosion electrochemistry test [17].

\section{Experimental}

\subsection{Main Materials}

Sodium gluconate was purchased from Wujiang City Xiaolong Fine Chemical Co. Ltd., Hydrolyzed polmaleic anhydride (HPMA) was supplied by Daqing Fine Chemical Company of China. $\mathrm{Zn}^{2+}$ synergist and sulfamic acid were produced by Nanjing Fine Chemical Company. All chemicals were of analytical reagent grade. 
Double distilled water and analytical reagent-grade $\mathrm{CaCl}_{2}, \mathrm{NaHCO}_{3}$ were used for preparing the simulated cooling water. And the characteristics of the simulated cooling water were given in Table 1.

\subsection{Determination of Static Corrosion Inhibition Efficiency}

The static corrosion inhibition efficiency was tested by weight loss experiment, which was conducted in the simulated cooling water at $45^{\circ} \mathrm{C} \pm 1{ }^{\circ} \mathrm{C}$ using a thermostat. Dried and accurately weighed the polished carbon steel sheets. Then put the carbon steel sheets into a beaker with the $1 \mathrm{~L}$ the simulated cooling water with and without HS. Distilled water was supplied for evaporating every 4 hours. After a period of $72 \mathrm{~h}$, the carbon steel sheets were taken out, washed by ethanol, dried, and accurately weighed. The corrosion inhibition efficiency was calculated by the Formula (1).

$$
\mathrm{n}(\%)=\frac{M 0-M 1}{M 1} \times 100
$$

In the formula, $\mathrm{n}$ presents the corrosion inhibition efficiency, $M 0$ and $M 1$ are the values of the weight loss of carbon steel after 72 hours being immersed in the simulated cooling water without and with HS.

\subsection{The Static Scale Inhibition Test}

HS was infused into the $1 \mathrm{~L}$ solution containing 120 $\mathrm{mg} \cdot \mathrm{L}^{-1} \mathrm{Ca}^{2+}, 240 \mathrm{mg} \cdot \mathrm{L}^{-1} \mathrm{HCO}_{3}^{-}$. And the mixture was incubated for $10 \mathrm{~h}$ at $80^{\circ} \mathrm{C}$. After a period of $72 \mathrm{~h}$, the filter liquor was titrated by Ethylene Diamine Tetraacetic Acid (EDTA). The static scale inhibition efficiency was calculated by the Formula (2).

$$
R(\%)=\frac{V 0-V 1}{V 0-V 2} \times 100
$$

In the formula, $V 0$ is the amount of consumed EDTA of the sample without the addition of HS before incubation, $V 1$ is the amount of consumed EDTA of the sample with the addition of HS after incubation, and $V 2$ is the amount of consumed EDTA of the sample without the addition of HS after incubation.

Table 1. The simulated cooling water characterization data.

\begin{tabular}{ccccccc}
\hline Parameter & $\mathrm{pH}$ & Conductivity & $\begin{array}{c}\text { Total } \\
\text { hardness }\end{array}$ & $\begin{array}{c}\text { Total } \\
\text { alkalinity }\end{array}$ & Calcium Chloride \\
\hline Value & 7.66 & 692 & 295 & 15 & 144.26 & 273.05 \\
Units & - & $\mu \mathrm{S} \cdot \mathrm{cm}^{-1}$ & $\mathrm{mg} \cdot \mathrm{L}^{-1}$ & $\mathrm{mg} \cdot \mathrm{L}^{-1}$ & $\begin{array}{c}\mathrm{Ca}^{2+} \\
\mathrm{mg} \cdot \mathrm{L}^{-1}\end{array}$ & $\begin{array}{c}\mathrm{Cl}^{-} \\
\mathrm{mg} \cdot \mathrm{L}^{-1}\end{array}$ \\
\hline
\end{tabular}

\subsection{Electrochemical Experiments}

The electrochemical measurements were carried out in a cell with three-electrode mode; platinum sheet and saturated calomel electrode (SCE) were used as counter and reference electrodes.

The $1 \mathrm{~cm}^{2}$ steel sample was abraded, washed, finally immersed in the simulated cooling water. Polarization curves measurements were performed using SC350 Electrochemical System. When polarization curve test was carried out, the potential scan rate was adjusted to 0.01 $\mathrm{v} \cdot \mathrm{s}^{-1}$. Polarization curves could be achieved after data process.

\subsection{Surface Analyses}

Corrosion crystal morphology on the surface of carbon steel was observed by scanning electronic microscope (SEM). In this experiment, the carbon steel was immersed in water sample with and without HS at the dosage of $40 \mathrm{mg} \cdot \mathrm{L}^{-1}$, respectively. Afterwards the test coupon was washed with $98 \%(\mathrm{w} / \mathrm{w})$ anhydrous alcohol and dried. Accelerating voltage of the SEM was $25 \mathrm{kV}$, and amplification factor was 200 .

\section{Results and Discussion}

\subsection{Confirming the Optimal Dosage of HS}

The data in Table 2 indicated that the corrosion inhibition efficiency of HS increased as the dosage increased. And the corrosion inhibition efficiency reached more than $94 \%$, when the dosage higher than $40 \mathrm{mg} \cdot \mathrm{L}^{-1}$.

Table 2. Influence of the dosage of HS on corrosion inhibi-

\begin{tabular}{|c|c|c|c|c|}
\hline $\begin{array}{l}\text { Dosage } \\
\text { of } \mathrm{HS} \\
\left(\mathrm{mg} \cdot \mathrm{L}^{-1}\right)\end{array}$ & $\begin{array}{l}\text { No. of } \\
\text { the steel } \\
\text { sheets }\end{array}$ & $\begin{array}{c}\text { Weight loss } \\
\text { of carbon } \\
\text { steel }(\mathrm{g})\end{array}$ & $\begin{array}{l}\text { Average weight } \\
\text { loss of carbon } \\
\text { steel }(\mathrm{g})\end{array}$ & $\begin{array}{c}\text { Corrosion } \\
\text { inhibition } \\
\text { efficiency }(\%)\end{array}$ \\
\hline \multirow[t]{2}{*}{0} & 1085 & 0.2018 & & \\
\hline & & & 0.1966 & 0.00 \\
\hline 0 & 1083 & 0.1914 & & \\
\hline \multirow[t]{2}{*}{20} & 1792 & 0.0387 & & \\
\hline & & & 0.0373 & 81.02 \\
\hline 20 & 1797 & 0.0359 & & \\
\hline \multirow[t]{2}{*}{40} & 1081 & 0.0110 & & \\
\hline & & & 0.0112 & 94.30 \\
\hline 40 & 1795 & 0.0114 & & \\
\hline \multirow[t]{2}{*}{60} & 1794 & 0.0103 & & \\
\hline & & & 0.0101 & 94.86 \\
\hline 60 & 1798 & 0.0099 & & \\
\hline
\end{tabular}
tion efficiency. 


\subsection{Static Scale Inhibition Performance Analysis}

Figure 1 showed the scale inhibition performance of HS. When the dosage of $\mathrm{HS}$ changed from 0 to $50 \mathrm{mg} \cdot \mathrm{L}^{-1}$, the scale inhibition efficiency of HS increased only from $0 \%$ to $98.97 \%$. The results showed that HS had excellent scale inhibition ability at the higher dosage, and the static scale inhibition efficiency of HS increased with the increase of the dosage of HS.

\subsection{Corrosion Electrochemistry Results Analysis}

The corrosion inhibition property of the HS was measured using electrochemical method, and the results were given in Table 3. And the inhibition efficiency of HS for the carbon steel corrosion was calculated by Formula (3):

$$
\eta=\frac{I_{\text {corr }}-I_{\text {corr }}^{\prime}}{I_{\text {corr }}} \times 100 \%
$$

where $I_{\text {corr }}$ and $I_{\text {corr }}$ are the corrosion current density values with and without HS, respectively.

The data in Table 3 showed that the self-corrosion current of carbon steel changed from $221 \mu \mathrm{A} \cdot \mathrm{cm}^{-2}$ in the absence of HS into $12 \mu \mathrm{A} \cdot \mathrm{cm}^{-2}$ at the dosage of $60 \mathrm{mg} / \mathrm{L}$ HS in the simulated cooling water. These results illustrated that HS had the properties of corrosion inhibition, the achieved efficiency reaching a maximum value of around $94 \%$, at the dosage of $60 \mathrm{mg} / \mathrm{L}$.

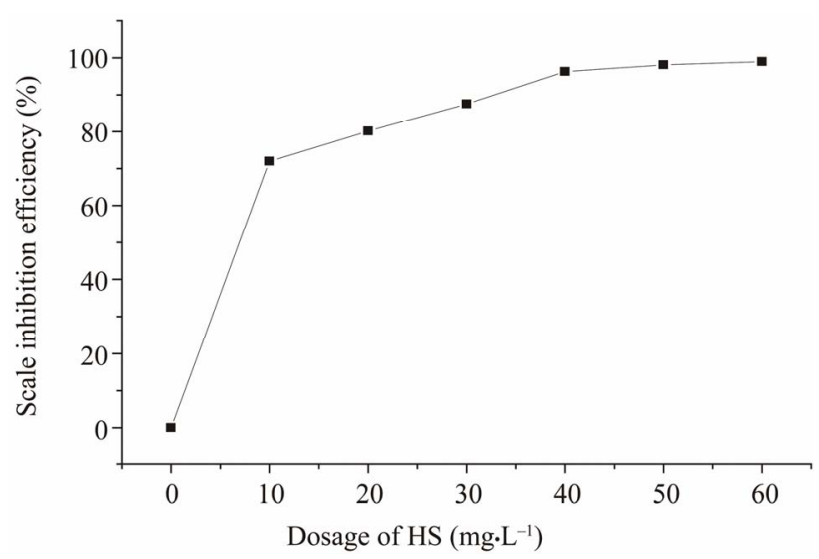

Figure 1. Influence of the dosage of HS on scale inhibition efficiency.

Table 3. Electrochemical parameter with different concentrations of HS in the simulated cooling water.

\begin{tabular}{cccc}
\hline $\begin{array}{c}\text { Concentration of } \\
\text { corrosion inhibitor } \\
\left(\mathrm{mg} \cdot \mathrm{L}^{-1}\right)\end{array}$ & $\begin{array}{c}E_{\mathrm{corr}}(v \mathrm{sSCE}) \\
(\mathrm{mV})\end{array}$ & $\begin{array}{c}I_{\text {corr }} \\
\left(\mu \mathrm{A} \cdot \mathrm{cm}^{-2}\right)\end{array}$ & $\begin{array}{c}\text { Corrosion rate } \eta \\
(\%)\end{array}$ \\
\hline 0 & -472 & 221 & 0 \\
20 & -451 & 42 & 81.00 \\
40 & -433 & 14 & 93.67 \\
60 & -426 & 12 & 94.55 \\
\hline
\end{tabular}

The polarization curves of carbon steel with the addition of HS in the simulated cooling water were given in Figure 2.

In Figure 2, the corrosion potential was shift to the positive after the inhibitor was added. The increasing in anodic current density indicated that the dissolution of the anode materials. Figure 2 showed the anode $I_{\text {corr }}$ was reduced from $201 \mu \mathrm{A} \cdot \mathrm{cm}^{-2}$ to $21 \mu \mathrm{A} \cdot \mathrm{cm}^{-2}$ after adding the inhibitor. It indicated that the anode corrosion process was inhibited. And the anodic inhibition effect was more significantly than the cathode with the inhibitor. Table 2 and Table 3 showed consistent results in the aspect of corrosion inhibition efficiency.

\subsection{Surface Analyses}

Figure 3 showed that the morphology of the corrosion products formed without HS was granular, irregular, and contains a number of voids. In comparison, the surface of the carbon steel with $40 \mathrm{mg} \cdot \mathrm{L}^{-1}$ of $\mathrm{HS}$ was flat and smooth. The scratch and few corrosion products on the surface of the carbon steel formed because of polishing hang-parcel. But there were little corrosion marks. Results illustrated that a complete coherent protective film formed on carbon steel surface after adding HS. It protected the carbon steel from corrosion by the simulated cooling water.

\section{Conclusion}

A composite eco-friendly phosphate-free corrosion and scale inhibitor HS has been developed using hydrolyzed polymaleic anhydride (HPMA), sodium gluconate, $\mathrm{Zn}^{2+}$ synergist and sulfamic acid. And the formula ratio of each component is 9:5:4:2. The experimental results showed that HS was a kind of good corrosion and scale

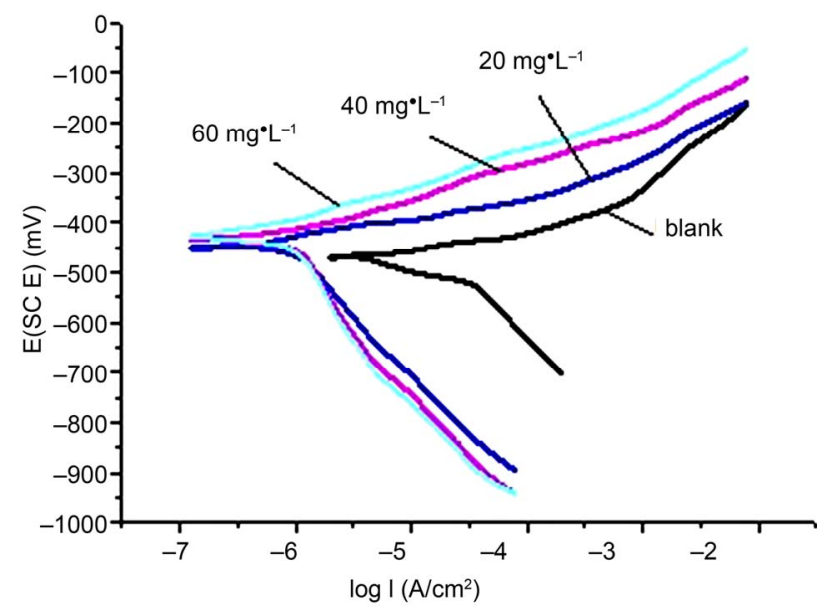

Figure 2. The polarization curve of blank and adding phosphate-free scale corrosion inhibitor treated samples in the simulated cooling water. 


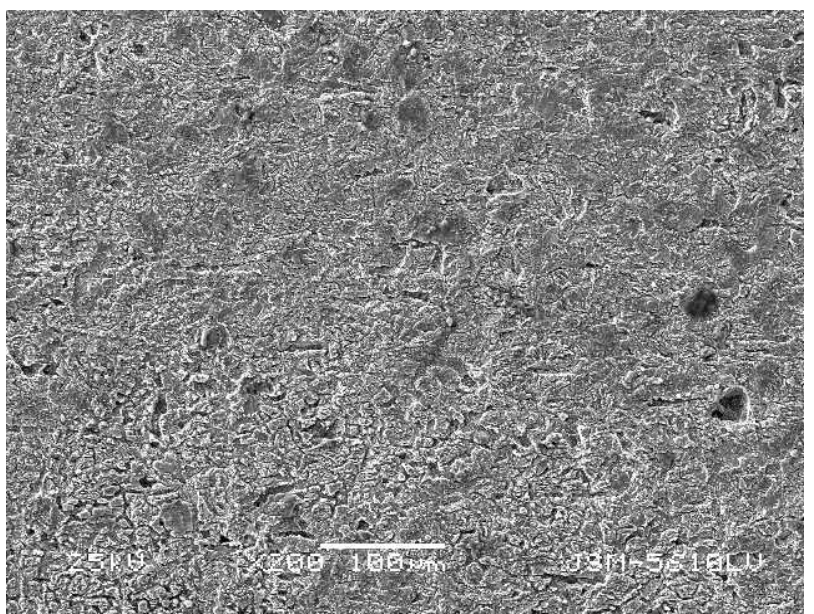

(a)

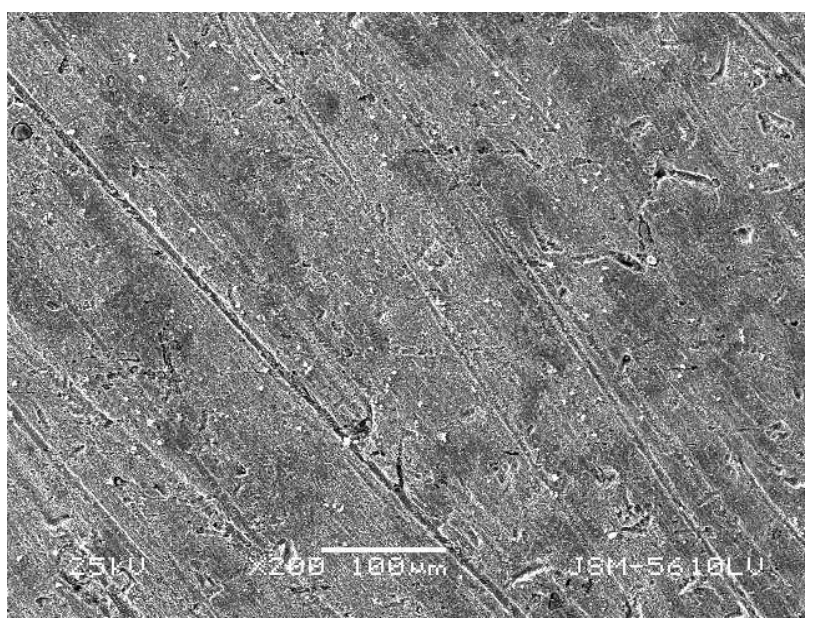

(a)

Figure 3. (a) and (b) were corrosion crystal on the carton steel surface without and with HS, respectively.

inhibitor whose corrosion inhibition rate and scale inhibition rate surpassed $94 \%$ and $98 \%$, respectively. Polarization curve test showed that HS was a kind of corrosion and scale inhibitor by mainly controlling anodic reaction. The surface morphology of the carbon steel was observed by SEM showed that a protective film was formed on the surface of the carbon steel with HS.

\section{Acknowledgements}

This project was supported by Ministry of Science and Technology in China of SME Technology Innovation Foundation and Department of Science and Technology in Hubei Province, China of Science and Technology Research Foundation, we thank those provided guidance and assistance.

\section{REFERENCES}

[1] S. H. You, D. H. Tseng, G. L. Guo and J. J. Yang, "The
Potential for the Recovery and Reuse of Cooling Water in Taiwan," Resources, Conservation and Recycling, Vol. 26, No. 1, 1999, pp. 53-70. doi:10.1016/S0921-3449(98)00075-5

[2] R. F. Zhuang and X. Xie, "Synthesis of 1-Amino-Ethylidenediphosphonic Acid (AEDP) and Its Performance as Scale and Corrosion Inhibitor," Chinese Journal of Applied Chemistry, No. 5, 1988, pp. 90-92.

[3] L. G. Qing, H. J. Yi, Z. Y. Ming, et al., "Acrylic AcidAllylpolyethoxy Carboxylate Copolymer Dispersant for Calcium Carbonate and Iron(III) Hydroxide Scales in Cooling Water Systems," Tenside Surfactants Detergents, Vol. 49, No. 3, 2012, pp. 216-224.

[4] B. Hassene and S. M. E. Hadi, "A Method of Making an Aqueous Dispersion of Polyaniline and Inhibiting Corrosion in Cooling Water," Desalination and Water Treatment, Vol. 44, No.1-3, 2012, pp. 190-196.

[5] C. G. Sinn, R. Dimova and M. Antonietti, "Isothermal titration Calorimetry of the Polyelectrolyte Water Interaction and Binding of $\mathrm{Ca}^{2+}$ : Effects Determining the Quality of Polymeric Scale Inhibitors," Macromolecules, Vol. 37, No. 9, 2004, pp. 3444-3450. doi:10.1021/ma030550s

[6] K. Ravichandran, N. M. Kumar, K. Subash and T. S. N. S. Narayanan, "Mannich Base Derivatives-A Novel Class of Corrosion Inhibitors for Cooling Water Systems," Corrosion Reviews, Vol. 19, No. 1, 2001, pp. 29-42.

[7] R. J. Ross, K. C. Low and J. E. Shannon, "Polyaspartate Scale Inhibitors-Biodegradable Alternatives to Polyacrylates," Materials Performance, Vol. 36, No. 4, 1997, pp. 53-57.

[8] L. J. Xi and Y. J. Zhang, "Study on the Corrosion and Scale Inhibitions of Phytic Acid," Industrial Water Treatment, Vol. 25, No. 12, 2005, pp. 27-28.

[9] R. C. Xiong, Q. Zhou and G. Wei, "Corrosion Inhibition of a Green Scale Inhibitor Polyepoxysuccinic Acid," Chinese Chemical Letters, Vol. 14, No. 9, 2003, pp. 955-957.

[10] D. Lzydor and F. Piotr, "Industrial Cooling Water Systems. Exploitation and environmentally Benign Total Inhibitive Protection," Przemysl Chemiczny, Vol.90, No. 5, 2011, pp. 737-741.

[11] X. P. Ou Yang and X. Q. Qiu, "Corrosion and Scale Inhibition Properties of Sodium Lignosulfonate and Its Potential Application in Recirculating Cooling Water System," Industry \& Engineering Chemistry Research, Vol. 45, No. 16, 2006, pp. 5716-5721. doi:10.1021/ie0513189

[12] C. A. Grillo, M. V. Mirífico, M. L. Morales, M. A. Reigosa and M. F. L. de Mele, "Assessment of Cytotoxic and Cytogenetic Effects of a 1,2,5-Thiadiazole Derivative on CHO-K1 Cells. Its Application as Corrosion Inhibitor," Journal of Hazardous Materials, Vol. 170, No. 2-3, 2009, pp. 1173-1178. doi:10.1016/j.jhazmat.2009.05.107

[13] R. Touir, N. Dkhireche, M. Ebn Touhami, M. Lakhrissi, B. Lakhrissi and M. Sfaira, "Corrosion and Scale Processes and Their Inhibition in Simulated Cooling Water Systems by Monosaccharides Derivatives: Part I: EIS Study," Desalination, Vol. 249, No. 3, 2009, pp. 922-928.

[14] J. L. Parks, A. Kashayap, A. Atassi, O. Schneider and M. Edwards, "Effect of Zinc and Orthophosphate Corrosion 
Inhibitors on Cement-Based Pipes," Journal American Water Works Association, Vol. 104, No. 1, 2012, pp. E1E14.

[15] R. Touir, M. Cenoui, M. El Bakri and M. Ebn Touhami, "Sodium Gluconate as Corrosion and Scale Inhibitor of Ordinary Steel in Simulated Cooling Water," Corrosion Science, Vol. 50, No. 6, 2008, pp. 1530-1537.

[16] S. Ramachandran, P. Fontanille and A. Pandey, "Glu- conic Acid: Properties, Applications and Microbial Production," Food Technology and Biotechnology, Vol. 44, No. 2, 2006, pp. 185-195.

[17] A. M. Abdel-Gaber, B. A. Abd-El-Nabey, E. Khamis and D. E. Abd-El-Khalek, "A Natural Extract as Scale and Corrosion Inhibitor for Steel Surface in Brine Solution," Desalination, Vol. 278, No. 1-3, 2011, pp. 337-342. doi:10.1016/j.desal.2011.05.048 